\title{
Subzero Temperature Dip-Coating of Sol-Gel Vanadium Pentoxide: Effect of the Deposition Temperature on the Film Structure, Morphology, and Electrochromic Properties
}

\author{
Afaf Almoabadi, ${ }^{1}$ Mohammed Alsawafta, ${ }^{1,2}$ Simona Badilescu, ${ }^{1}$ Victor Stancovski, ${ }^{3}$ \\ Tanu Sharma, ${ }^{4}$ Ralf Brüning, ${ }^{4}$ and Vo-Van Truong ${ }^{1}$ \\ ${ }^{1}$ Department of Physics, Concordia University, Montreal, QC, Canada H4B 1 R6 \\ ${ }^{2}$ American University of Kuwait, 13034 Safat, Kuwait \\ ${ }^{3}$ LogiCoul Solutions LLC, Sterling Heights, MI 48313, USA \\ ${ }^{4}$ Department of Physics, Mount Allison University, Sackville, NB, Canada E4L 1E2 \\ Correspondence should be addressed to Vo-Van Truong; truong.vo-van@concordia.ca
}

Received 4 August 2015; Accepted 13 December 2015

Academic Editor: Peng Zhou

Copyright (C) 2016 Afaf Almoabadi et al. This is an open access article distributed under the Creative Commons Attribution License, which permits unrestricted use, distribution, and reproduction in any medium, provided the original work is properly cited.

\begin{abstract}
Vanadium pentoxide sol-gel prepared thin films were deposited on indium-tin-oxide (ITO) substrates by dip-coating at a subzero temperature $\left(-10^{\circ} \mathrm{C}\right)$. The structure, morphology, and optical and electrochromic properties of dense and porous vanadium oxide films coated at low temperature were determined and compared to those of the corresponding films deposited under roomtemperature conditions. The results indicated that, in the films coated at $-10^{\circ} \mathrm{C}$, a residual compressive stress exists that would originate from the formation of microvoids during the deposition. These microvoids are preserved during the heat treatment of the films. The microvoid morphology would favor the formation of nanostructures that would be responsible for the improved electrochromic properties of the subzero dip-coated films. Low-temperature coated films, heated at $450^{\circ} \mathrm{C}$ for several hours, undergo the transformation from a layered to a highly uniform nanorod structure that would be an important feature for different applications.
\end{abstract}

\section{Introduction}

Due to its fundamental and technological interest, vanadium pentoxide has been an important topic of research for many years. Because of the high charge intercalation capacity of vanadium pentoxide films, they are successfully used in energy storage/conversion devices, as cathodes for secondary lithium ion batteries and electrochromic devices. Other interesting applications encompass optical filters, reflectance mirrors, and surfaces with tunable emittance for temperature control of space vehicles [1]. Vanadium oxide is used as cathode material in lithium batteries [2], in bolometric detectors [3], and as ferromagnetic nanotubes [4-6]. Important examples are the use of vanadium oxide-based catalysts in the synthesis of bulk chemicals like $\mathrm{SO}_{3}$, propene, and so forth and in the reduction of environmental pollution, for example, the reduction of nitrogen oxides $\mathrm{NO}_{x}$ in the exhaust gas from power plants.

Vanadium oxide thin films, as many other transition metal oxides, have been prepared using physical techniques such as sputtering [7-9], thermal evaporation [10], pulsed laser deposition [11], e-beam deposition [12], flash-evaporation [13], chemical vapor deposition [14], and spray pyrolysis [15].

The thermal evaporation and sputtering methods were among the first methods that were used for the fabrication and characterization of vanadium pentoxide films and they continue to be used today for specific applications. However, after the development of sol-gel route, many of the studies in the field of electrochromism (EC) were based on sol-gel methods because of the simplicity and the milder conditions. Sol-gel synthesis has proven to be one of the most convenient 
methods to prepare electrochromic nanostructured vanadium pentoxide films. In the sol-gel technique, the deposition sol is prepared by the hydrolysis and condensation of a vanadium oxide precursor solution. The method is relatively simple and the concentration of reactants can be controlled accurately. There is today a plethora of precursor molecules that are both organic and inorganic, and, generally, the chemistry of the reactions is well known. The solutions can be easily coated on indium-tin-oxide (ITO) substrates by dip- and spin-coating, by using relatively simple equipment [16-21].

Kim et al. [22] recently developed a new technique of dipcoating, termed "sol-gel synthesis at subzero temperatures" and used it for the deposition of zinc oxide thin films. They have studied the effect of the dip-coating temperature on the structure and optical properties of the films and have found that, at subzero temperatures, the deposition rate is higher because of the higher viscosity of the solution.

In our previous work, porous vanadium pentoxide films were prepared by using template methods. It has been reported that template sol-gel prepared vanadium oxide films yield, after removing the template, meso- (pores in the size range of 2 to $20 \mathrm{~nm}$ ) or macroporous films with significantly enhanced electrochromic properties [23-32]. The morphology and optical and electrochromic properties of the macro- and mesoporous films, prepared in the presence of structure-directing agents, have been compared with those of dense films [23]. The transformation of the lamellar into a nanorod structure, observed when the film is heated at $400-$ $500^{\circ} \mathrm{C}$ for several hours, resulted in the development of an elegant method for the synthesis of vanadium oxide nanorods [23]. We intended to investigate this transformation under different conditions by dip-coating the precursor solution at a low (subzero) temperature and to take advantage of the higher rate of deposition associated with this method [22]. The aim of this work is to synthesize nanorod films with a greater uniformity in size that would be useful for optoelectronic devices. It has been shown that length uniformity is of great importance in fabrication of nanorods and nanowires as building blocks for applications that involve electron and ion flow [33]. In addition, because of the high aspect ratio, low dimensional nanostructures such as nanowires and nanorods have many nanotips that make them interesting for field emission displays $[34,35]$. In the present work, we focus on the changes in structure and morphology of the $\mathrm{V}_{2} \mathrm{O}_{5}$ film that accompany the low-temperature dip-coating as well as on the optical, electrochromic, and electrical characteristics of the films dip-coated at subzero temperatures.

\section{Experimental}

The preparation and deposition of $\mathrm{V}_{2} \mathrm{O}_{5}$ thin films are described in detail in our previous paper [23]. Briefly, $1.2 \mathrm{~mL}$ of vanadium oxytriisopropoxide and $100 \mu \mathrm{L}$ of acetic acid are dissolved in $30 \mathrm{~mL}$ isopropyl alcohol and stirred during 2 hours when a yellow-orange solution is obtained. The solution is transferred in a small beaker and kept in the freezer for $40 \mathrm{~min}$, until the temperature of the solution reaches $-10^{\circ} \mathrm{C}$. The solution is immediately coated on an ITO substrate and then annealed at varying temperatures.
TABLE 1: Conditions used for the fabrication of $\mathrm{V}_{2} \mathrm{O}_{5}$ dense and porous films.

\begin{tabular}{lcc}
\hline Sample & $\begin{array}{c}\text { Annealing/drying } \\
\text { temperature }\left({ }^{\circ} \mathrm{C}\right)\end{array}$ & Type of the template \\
\hline A & 27 & No \\
B & 300 & No \\
C & 450 & No \\
D & 500 & No \\
E & 450 & Triblock copolymer, 20\% \\
F & 450 & PS 600 nm \\
\hline
\end{tabular}

Before depositing each successive layer, the coating solution was kept in the freezer, until the temperature has reached $-10^{\circ} \mathrm{C}$ and stabilized at this temperature. For all the experiments, the films were built up by coating successively five layers on the ITO substrate and annealed in different ways (for the conditions, see Table 1). For the polystyrene (PS) microsphere-template films, the template was built up by using the thermal convection process [24]. Microspheres with a diameter of $0.6 \mu \mathrm{m}$ were used in this work. After dip-coating and annealing the composite films, polystyrene microspheres were removed from the samples, either by annealing or by extraction with tetrahydrofuran (THF).

The nonionic surfactant, $\mathrm{EO}_{20} / \mathrm{PO}_{70} / \mathrm{EO}_{20}$ (Pluronic $\mathrm{P} 123$ ), was dissolved in the coating solution (concentration of $20 \%$ ). To remove the triblock copolymer from the film, the samples were soaked in a mixture of water-ethanol $(1: 1)$ for $1 \mathrm{~h}$, or they were heat-treated at high temperatures. Table 1 shows the parameters used for the fabrication of $\mathrm{V}_{2} \mathrm{O}_{5}$ films (A-F) prepared, either at room temperature or under the subzero condition $\left(-10^{\circ} \mathrm{C}\right)$, with and without using a template material.

Vanadium oxide films were characterized morphologically by using Scanning Electron Microscopy (SEM). Atomic Force Microscopy (AFM) was used to measure the thickness of the film and the crystalline structure was determined by using X-ray diffraction (XRD). XRD measurements were carried out in symmetric reflection mode with a custombuilt $\theta-\theta$ diffractometer equipped with pyrolytic graphite monochromator and analyzer crystals. $\mathrm{Cu} \mathrm{K}$-alpha radiation $(\lambda=0.15418 \mathrm{~nm})$ was used for the measurements. Raman spectroscopy was used to evaluate the strain in the films. The electrochromic properties were evaluated through cyclic voltammetry and the optical modulation was measured simultaneously by UV-Visible spectroscopy. A threeelectrode cell was used, where the vanadium oxide film on the ITO/glass substrate is the working electrode, $\mathrm{Ag} / \mathrm{AgCl}$ the reference electrode, and Pt the counter electrode. The electrolyte used in the experiment was a $1 \mathrm{M}$ solution of lithium perchlorate in propylene carbonate. Impedance measurements were performed in a three-electrode system setup, by applying a $10 \mathrm{mV}$ ac signal over the frequency range of $0.1 \mathrm{~Hz}$ to $500 \mathrm{kHz}$ (versus $\mathrm{Ag} / \mathrm{AgCl}$ ) at the vanadium oxide film using a Gamry Reference 3000 potentiostat/galvanostat/ZRA. The analysis of the results was done using the Gamry Echem Analyst software, version 6.24 . 
TABLE 2: Crystallographic data corresponding to subzero dip-coated vanadium pentoxide films.

\begin{tabular}{lcccccc}
\hline Sample & Deposition temperature & $a, \mathrm{~nm}$ & $b, \mathrm{~nm}$ & $c, \mathrm{~nm}$ & ${\text { Unit cell volume, } \mathrm{nm}^{3}}^{\text {Size, }^{\circ}}$ \\
\hline \multirow{2}{*}{$300^{\circ} \mathrm{C}$} & $-10^{\circ} \mathrm{C}$ & 1.1477 & 0.35745 & 0.43858 & 0.1799 & 14.54 \\
& $\mathrm{RT}$ & 1.14400 & 0.35925 & 0.4375 & 0.1798 & 12.27 \\
\hline \multirow{2}{*}{$500^{\circ} \mathrm{C}$} & $-10^{\circ} \mathrm{C}$ & 1.1478 & 0.3521 & 0.4380 & 0.1770 & 0.1813 \\
& $\mathrm{RT}$ & 1.14540 & 0.36087 & 0.4387 & 0.17955 \\
\hline Literature data & & 1.1516 & 0.35656 & 0.43727 & 23.14 \\
\hline
\end{tabular}

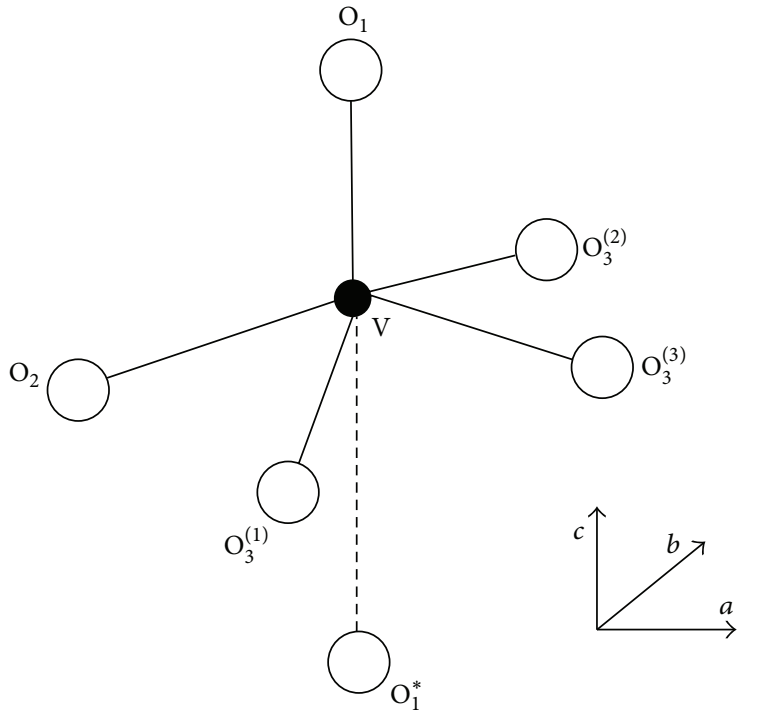

FIGURE 1: Coordination of vanadium with oxygen in vanadium pentoxide.

\section{Results and Discussion}

3.1. Effect of the Subzero Temperature Deposition on the Structure and Morphology of the Film. Vanadium pentoxide has an orthorhombic structure and crystallizes in the Pmmn space group, with the unit cell parameters: $a=11.51 \AA, b=3.563 \AA$, and $c=4.369 \AA$.

The layered structure of orthorhombic $\mathrm{V}_{2} \mathrm{O}_{5}$ is built up of edge-sharing $\mathrm{VO}_{5}$ square pyramids. As shown in Figure 1, vanadium atoms form five bonds with the atoms of oxygen: one with $\mathrm{O}_{1}$ atoms, one with $\mathrm{O}_{2}$ atoms, and three with $\mathrm{O}_{3}$ atoms. The shortest bond is the one with $\mathrm{O}_{1}(1.585 \AA)$ and this oxygen is usually called the "vanadyl" oxygen. The $\mathrm{O}_{2}$ oxygen is called the "bridging" oxygen and the $\mathrm{O}_{3}$ oxygen atoms are called "chain" oxygen. The layers are held together by weak $\mathrm{V}-\mathrm{O}_{1}^{*}$ bonds in the crystallographic $c$ direction.

Figure 2 shows the XRD pattern of the subzero dip-coated $\mathrm{V}_{2} \mathrm{O}_{5}$ film, annealed for one hour in air at 300 and $500^{\circ} \mathrm{C}$, respectively. The data are shown as a function of modulus of the scattering vector; $q=4 \pi \lambda^{-1} \sin \theta$, where $2 \theta$ is the scattering angle. The signals include the contributions from the $\mathrm{V}_{2} \mathrm{O}_{5}$ film and the ITO substrate. Reference patterns from the JCPDS database are indicated by the vertical lines. Based on a fit to the data (red line), the dimensions of the orthorhombic unit cell for the subzero dip-coated films are shown in Table 2.
TABLE 3: Position of the Raman bands in the spectra corresponding to the subzero and room-temperature dip-coating.

\begin{tabular}{lccc}
\hline \multicolumn{3}{c}{ Position of Raman bands $\left(\mathrm{cm}^{-1}\right)$} & Assignment \\
$\mathrm{RT}^{\mathrm{a}}$ & $\mathrm{LT}^{\mathrm{b}}$ & $\Delta \nu^{*}\left(\mathrm{~cm}^{-1}\right)$ & \\
\hline 997.49 & 997.96 & +0.47 & $\nu($ terminal O) \\
708.44 & 711.26 & +2.82 & $\nu(\mathrm{V} 2-\mathrm{O})$ \\
528.15 & 532.16 & +4.01 & $\nu(\mathrm{V} 3-\mathrm{O})$ \\
484.75 & 486.71 & +1.96 & $\delta(\mathrm{V}-\mathrm{O}-\mathrm{V})$ \\
406.06 & 408.03 & +1.97 & $\delta(\mathrm{V}=\mathrm{O})$ \\
303.32 & 303.66 & +0.34 & - \\
283.97 & 286.95 & +2.98 & $\delta(\mathrm{V}=\mathrm{O})$ \\
\hline
\end{tabular}

${ }^{a}$ Room-temperature dip-coated and annealed at $500^{\circ} \mathrm{C}$.

${ }^{\mathrm{b}}$ Low-temperature dip-coated and annealed at $500^{\circ} \mathrm{C}$

${ }^{*}$ LT-RT.

In general, we find that the lattice parameters of the vanadium oxide crystallites are close to the literature values. However, the parameter $a$ is found to be somewhat larger in the film deposited at $-10^{\circ} \mathrm{C}$ and annealed at $500^{\circ} \mathrm{C}$ than in the film dip-coated at room temperature and annealed under the same conditions (1.1477 nm compared to $1.1454 \mathrm{~nm}$ ), while $b$ appears to be shorter $(0.3521 \mathrm{~nm}$ compared to $0.36087 \mathrm{~nm})$. The smallest unit cell volume corresponds to the subzero deposited film, annealed at $500^{\circ} \mathrm{C}\left(0.1770 \mathrm{~nm}^{3}\right)$. After annealing at $300^{\circ} \mathrm{C}$, the crystallite size estimate by the Scherrer equation is $15 \mathrm{~nm}$, whereas upon annealing at $500^{\circ} \mathrm{C}$ the crystals grow to $23 \mathrm{~nm}$.

In order to account for the changes observed in the crystallographic data, the Raman spectra of the film dip-coated at $-10^{\circ} \mathrm{C}$ have been investigated. Figure 3 shows the Raman spectrum of the film dip-coated at $-10^{\circ} \mathrm{C}$. The positions and assignments of the Raman bands corresponding to the subzero and room-temperature dip-coated samples are shown in Table 3 . The point symmetry group of $\mathrm{V}_{2} \mathrm{O}_{5}$ is $\mathrm{D}_{2 \mathrm{~h}}$.

Table 3 shows that all the Raman bands of the low-temperature dip-coated samples are at higher wave numbers than those of the RT-coated samples annealed at the same temperature, that is, $500^{\circ} \mathrm{C}$. The most sensitive bands (the most affected by the temperature of the coating) are the V2$\mathrm{O}$ and V3-O stretching bands and the vanadyl bending band. Both XRD and Raman spectroscopy results indicate that a residual compressive stress (or strain) exists in the subzero dip-coated $\mathrm{V}_{2} \mathrm{O}_{5}$ film. This stress may originate in a difference in the thermal expansion coefficients of the thin film and its substrate (thermal mismatch stress) and/or in the grain structure, fabrication process, and so forth. In addition, the stress is possibly due to a nonuniformity through the depth, 


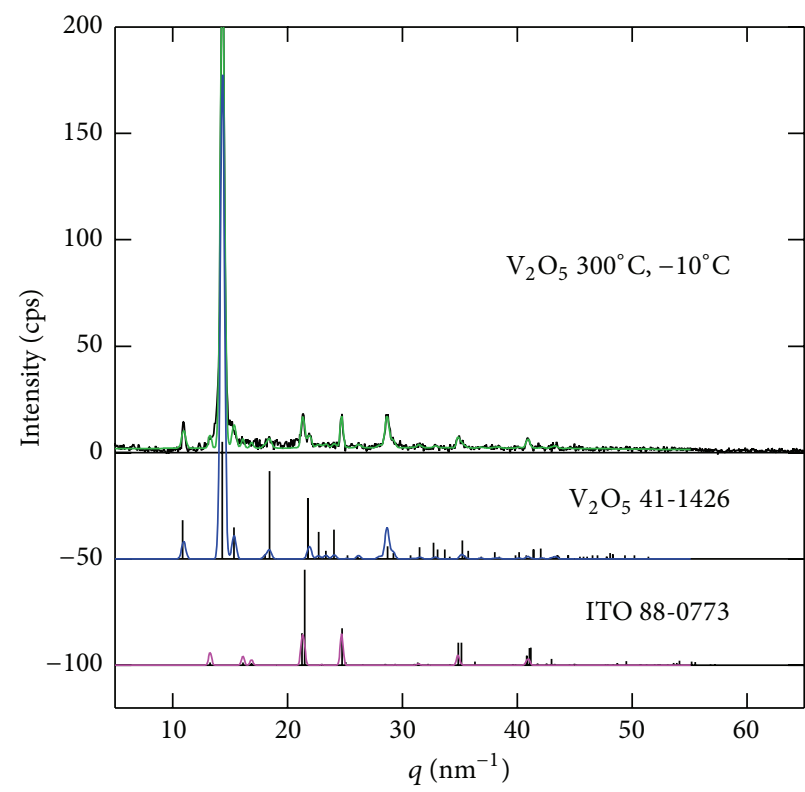

(a)

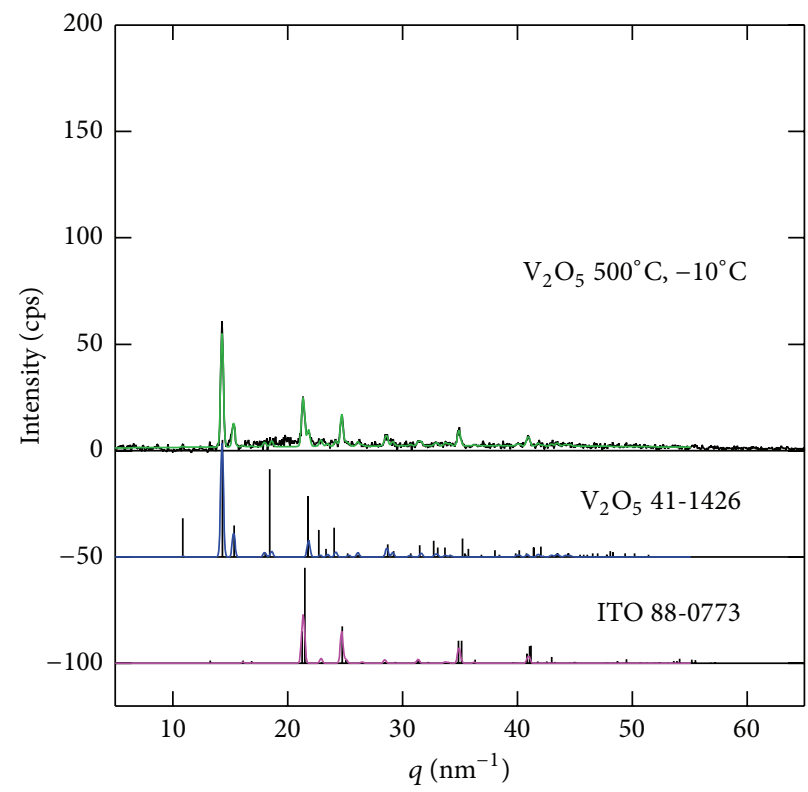

(b)

FIGURE 2: XRD pattern of the vanadium oxide films, dip-coated at $-10^{\circ} \mathrm{C}$ and annealed at $300^{\circ} \mathrm{C}$ (a) and $500^{\circ} \mathrm{C}$ (b). X-ray diffraction signal of an orthorhombic $\mathrm{V}_{2} \mathrm{O}_{5}$ film (ICDD 41-1426) on an ITO covered glass substrate, annealed at $500^{\circ} \mathrm{C}$ for one hour. The signal from the glass substrate has been subtracted. The fit (red line) includes the contributions from $\mathrm{V}_{2} \mathrm{O}_{5}$ and ITO to the signal.

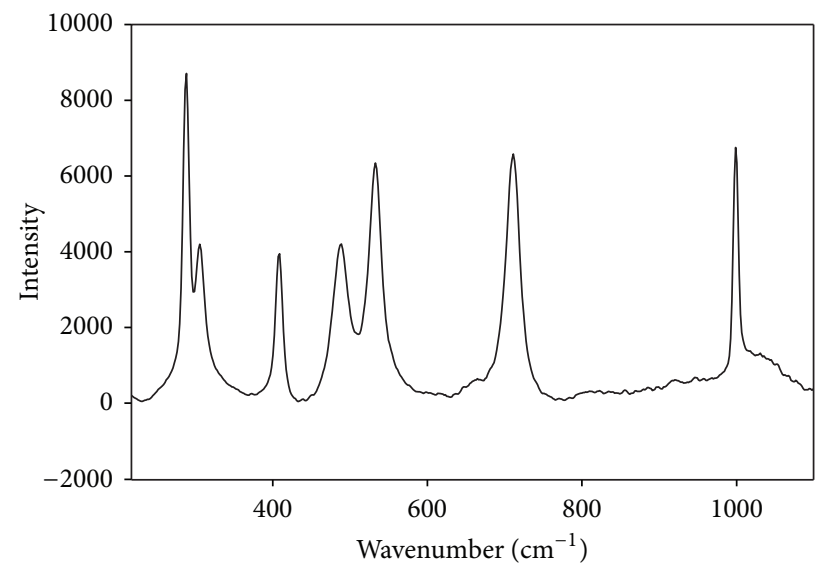

Figure 3: Raman spectrum of the $\mathrm{V}_{2} \mathrm{O}_{5}$ film dip-coated at $-10^{\circ} \mathrm{C}$ and annealed at $500^{\circ} \mathrm{C}$. The Raman bands were assigned according to $[12,13]$.

for example, the formation of microvoids when by-products may escape as gases. Due to the slow diffusion of atoms at low temperature, there remain empty spaces in the film that result in an intrinsic stress. The microvoids formed during the lowtemperature deposition can be clearly seen in the SEM images of the films (Figure 4).

However, after heating the subzero coated film to $450^{\circ} \mathrm{C}$ for 3 hours, the formation of nanorods can be observed as it has been noted in the case of the room-temperature coated films.

The SEM image in Figure 5 shows that, indeed, the nanorods, formed by the extended annealing of the lowtemperature deposited film, are more uniform than those formed from a layered film, dip-coated at room temperature (Figure 5(a)). This is a significant result as it opens the door to the preparation of uniform nanorods with potentially important applications.

The results show that the subzero temperature deposition of the $\mathrm{V}_{2} \mathrm{O}_{5}$ films significantly varied its photoluminescence properties, as seen in Figure 6.

Figure 6(a), corresponding to the subzero deposited film, displays no PL bands at room temperature, and the bands around $750 \mathrm{~nm}$, in the case of the films annealed at $300^{\circ} \mathrm{C}$ and $500^{\circ} \mathrm{C}$, have almost the same intensity. The second band is missing, possibly, because of less structural defects such as vacancies in the crystal lattice, in the low-temperature deposited film.

The PL spectrum corresponding to the room-temperature coated film (Figure 6(b)) shows a shift of the band, from 760 to $705 \mathrm{~nm}$ when the film is heated to $300^{\circ} \mathrm{C}$, and the intensity of the emission at $700 \mathrm{~nm}$ is considerably higher than when the film was heat-treated at $500^{\circ} \mathrm{C}$ in air. It can be seen that the intensity of the second PL band, around $880 \mathrm{~nm}$, is slightly increasing with the annealing temperature. Taking into account the phase change observed at $500^{\circ} \mathrm{C}$, the high intensity of the visible light emission could be explained by oxygen vacancies or/and the $\mathrm{V}^{4+}$ defects that would appear during the formation of the nanorods [36].

3.2. Mechanism of the Formation of Nanorods by High-Temperature Annealing of the Low-Temperature Dip-Coated $\mathrm{V}_{2} \mathrm{O}_{5}$ Films. In order to investigate the mechanism of transformation of the layered structure in nanorods, in the case of the subzero temperature dip-coated films, the time of annealing was varied between 1 and 3 hours. The SEM images 


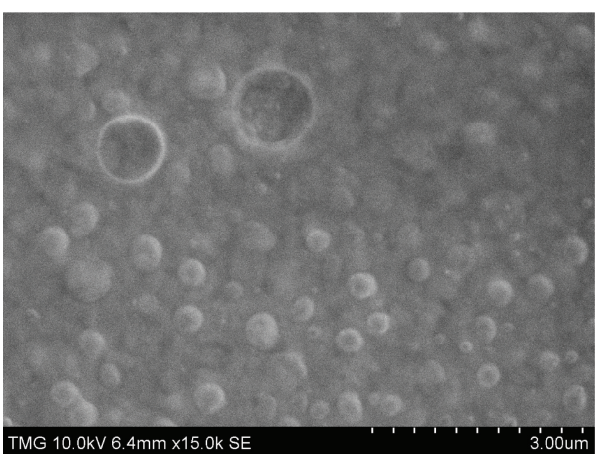

(a)

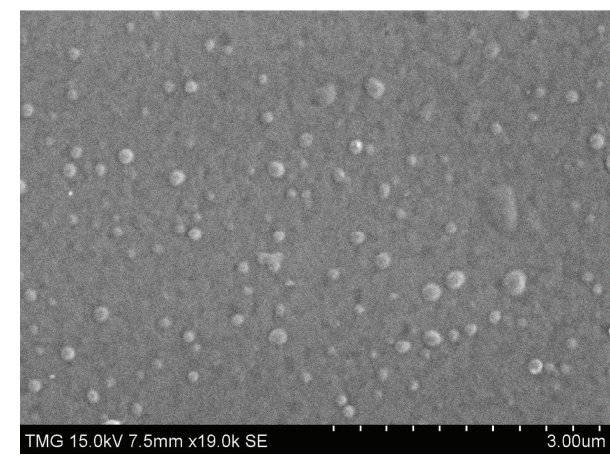

(b)

FIgURE 4: SEM image of the $\mathrm{V}_{2} \mathrm{O}_{5}$ film dip-coated at $-10^{\circ} \mathrm{C}$ and annealed at $300^{\circ} \mathrm{C}$ (a) and the film dip-coated at room temperature and annealed at $300^{\circ} \mathrm{C}(\mathrm{b})$.

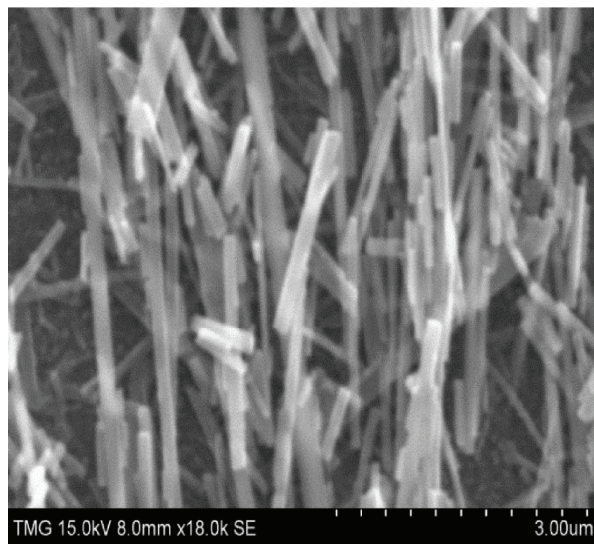

(a)

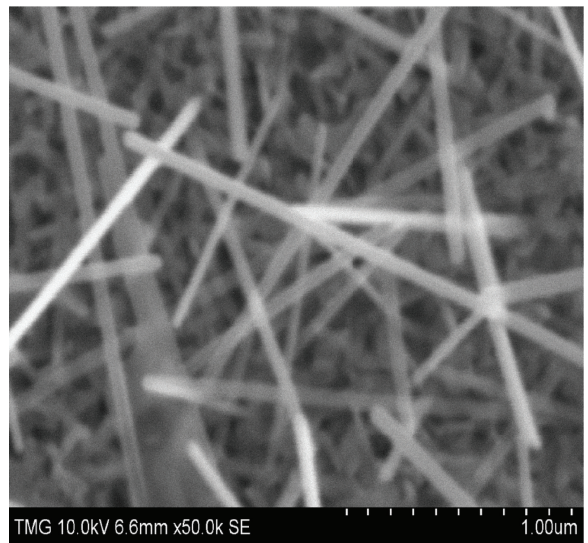

(b)

FIGURE 5: SEM image of the $\mathrm{V}_{2} \mathrm{O}_{5}$ nanorod film, dip-coated at room temperature (a) and $-10^{\circ} \mathrm{C}$, (b) both annealed at $450^{\circ} \mathrm{C}$ (sample template with the triblock copolymer).

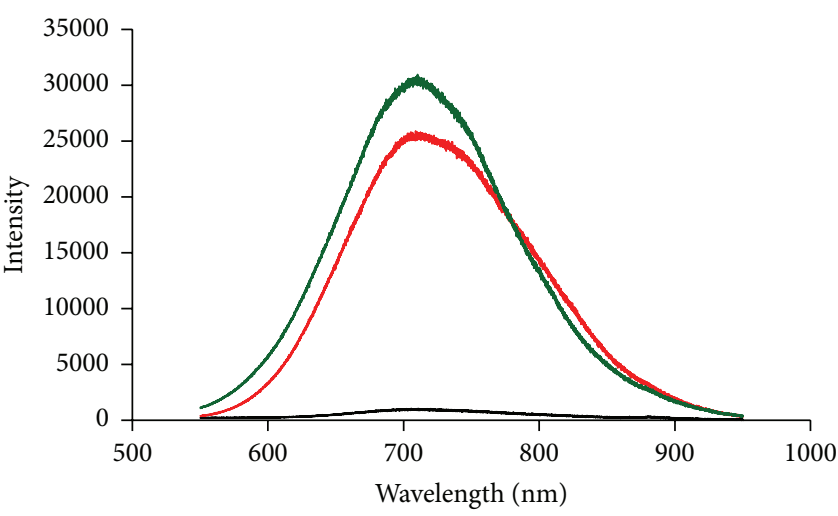

(a)

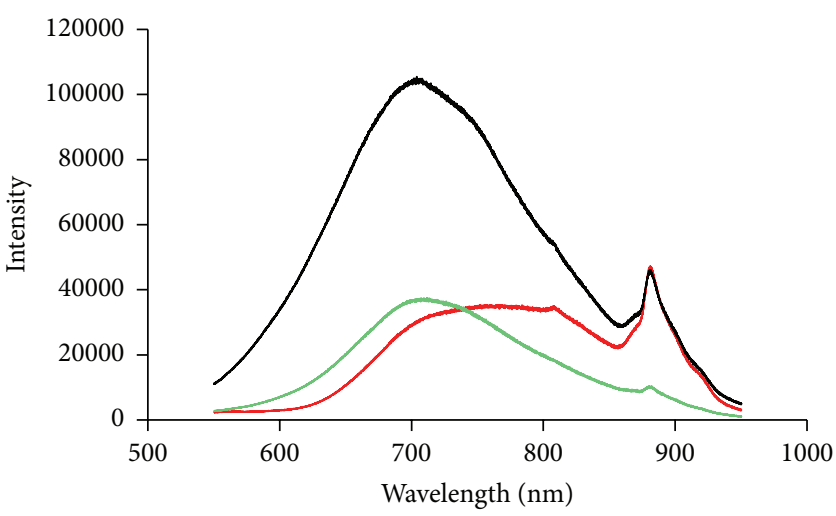

(b)

Figure 6: Photoluminescence spectra of the subzero temperature dip-coated film (a) and of the RT deposited film (b), both annealed at $27^{\circ} \mathrm{C}$ (green), $300^{\circ} \mathrm{C}$ (red), and $500^{\circ} \mathrm{C}$ (black), respectively. 


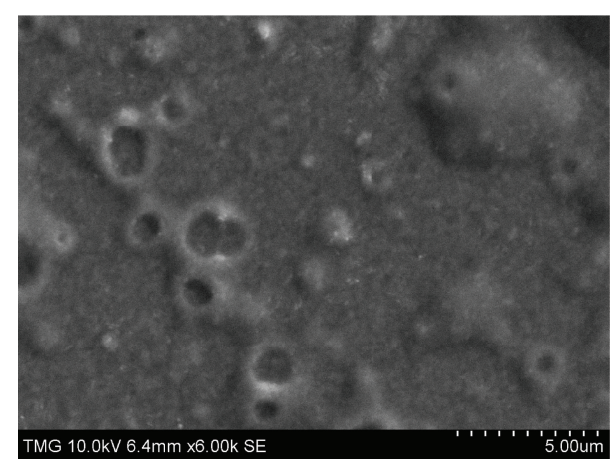

(a)

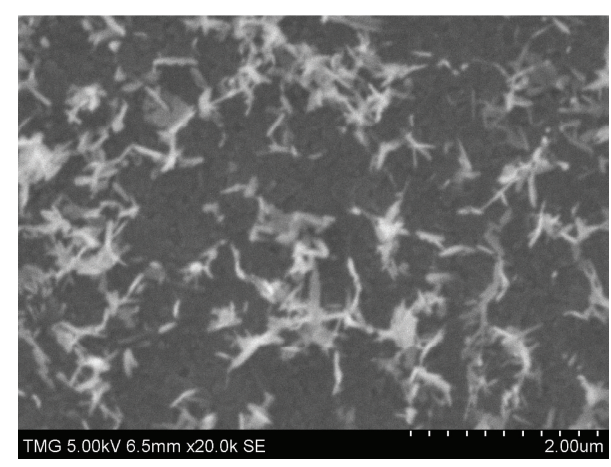

(b)

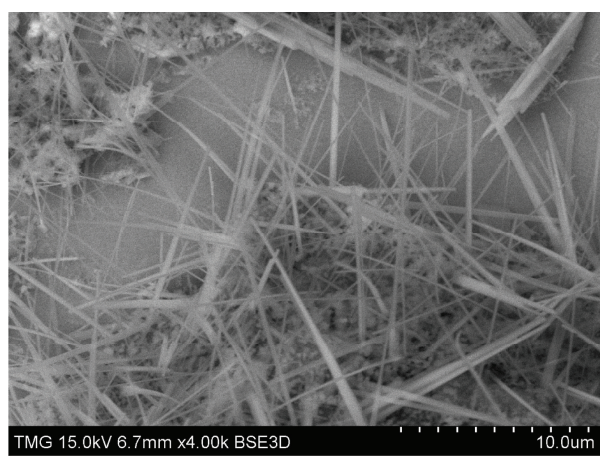

(c)

FIGURE 7: SEM image of the film template with PS microspheres $(600 \mathrm{~nm})$, dip-coated at subzero temperature, and annealed at $450^{\circ} \mathrm{C}$ for $1 \mathrm{~h}$ (a), 2 hours (b), and 3 hours (c).

TABLE 4: Coloration efficiency (CE) of the subzero coated dense films, subsequently annealed at different temperatures.

\begin{tabular}{|c|c|c|c|c|c|c|c|}
\hline \multirow{2}{*}{ Sample } & \multirow{2}{*}{ Temperature of drying/annealing $\left({ }^{\circ} \mathrm{C}\right)$} & \multicolumn{2}{|c|}{$Q(\mathrm{mC})$} & \multicolumn{2}{|c|}{$\mathrm{CE}\left(\mathrm{cm}^{2} / \mathrm{C}\right)(600 \mathrm{~nm})$} & \multicolumn{2}{|c|}{$\mathrm{CE}\left(\mathrm{cm}^{2} / \mathrm{C}\right)(843 \mathrm{~nm})$} \\
\hline & & $\mathrm{RT}^{*}$ & $\mathrm{SZT}^{* *}$ & $\mathrm{RT}^{*}$ & $\mathrm{SZT}^{* *}$ & $\mathrm{RT}^{*}$ & $\mathrm{SZT}^{* *}$ \\
\hline $\mathrm{A}$ & RT & 9 & 14 & 19 & 32 & 3 & 13 \\
\hline $\mathrm{B}$ & $300^{\circ} \mathrm{C}$ & 18 & 16 & 28 & 4 & 28 & 44 \\
\hline $\mathrm{C}$ & $450^{\circ} \mathrm{C}$ & 23 & 19 & 22 & 23 & 51.9 & 73 \\
\hline $\mathrm{D}$ & $500^{\circ} \mathrm{C}$ & 13 & 19 & 24 & 53 & 68 & 38 \\
\hline
\end{tabular}

${ }^{*}$ Room temperature.

** Subzero temperature.

of the resultant films are shown in Figure 7. The figure shows that, after only one hour of heating, the film still shows the microvoids; after two hours, some star-like structures are formed that will lead after an extended heating to the formation of nanorods.

\subsection{Effect of the Subzero Temperature Deposition on the Elec-} trochromic Properties. In this section, we compare the electrochromic (EC) properties, namely, the coloration efficiency and diffusion coefficients of the subzero coated films, with those of the films deposited under the same conditions at room temperature, thoroughly investigated in our previous work [23]. The EC measurements were carried out both on the dense films and on those fabricated by using structuredirecting molecules, that is, on "template films." The intercalated charge $(Q)$ and the coloration efficiency (CE) in the visible $(600 \mathrm{~nm})$ and near-infrared $(843 \mathrm{~nm})$ for the dense and template films are shown in Tables 4 and 5, respectively.

The thickness and the roughness of both films were measured by scratched films, by using AFM measurements. The results indicated that, indeed, the thickness of films dip-coated at $-10^{\circ} \mathrm{C}$, under precisely the same conditions, is almost twice, compared with the RT-deposited films (around 130 versus $66 \mathrm{~nm}$, resp.). This result is in agreement with the data found for the subzero coated $\mathrm{ZnO}$ films and accounted for by a higher deposition rate because of the increased viscosity of the coating solution at low temperatures [22]. The roughness of the films was found quite high, around $63 \mathrm{~nm}$, compared to $54 \mathrm{~nm}$ corresponding to the RT-deposited film.

Figure 8(a) shows a typical voltammogram of a subzero deposited (and annealed at $500^{\circ} \mathrm{C}$ ) film and Figure 8(b) illustrates the optical modulation corresponding to the same 
TABLE 5: Coloration efficiency (CE) and diffusion coefficient of $\mathrm{Li}^{+}$in porous films prepared with structure directing agents.

\begin{tabular}{|c|c|c|c|c|c|c|c|c|c|}
\hline \multirow{2}{*}{ Sample } & \multirow{2}{*}{ Template film } & \multicolumn{2}{|c|}{$Q(\mathrm{mC})$} & \multicolumn{2}{|c|}{$\mathrm{CE}\left(\mathrm{cm}^{2} / \mathrm{C}\right)(600 \mathrm{~nm})$} & \multicolumn{2}{|c|}{$\mathrm{CE}\left(\mathrm{cm}^{2} / \mathrm{C}\right)(843 \mathrm{~nm})$} & \multicolumn{2}{|c|}{$D\left(\mathrm{~cm}^{2} / \mathrm{s}\right)$} \\
\hline & & RT & SZT & $\mathrm{RT}$ & SZT & $\mathrm{RT}$ & SZT & $\mathrm{RT}$ & SZT \\
\hline $\mathrm{E}$ & $\begin{array}{l}\text { Copolymer }(20 \%) \text { extracted with a } \\
\text { mixture of water and ethanol }\end{array}$ & 18 & 13 & 34 & 15 & 28 & 35 & $2.8 \times 10^{-10}$ & $2.0 \times 10^{-10}$ \\
\hline $\mathrm{F}$ & PS $(600 \mathrm{~nm})$ annealing at $450^{\circ} \mathrm{C}$ & 9 & 15 & 10 & 15 & 33 & 57 & $8.3 \times 10^{-11}$ & $1.5 \times 10^{-10}$ \\
\hline
\end{tabular}

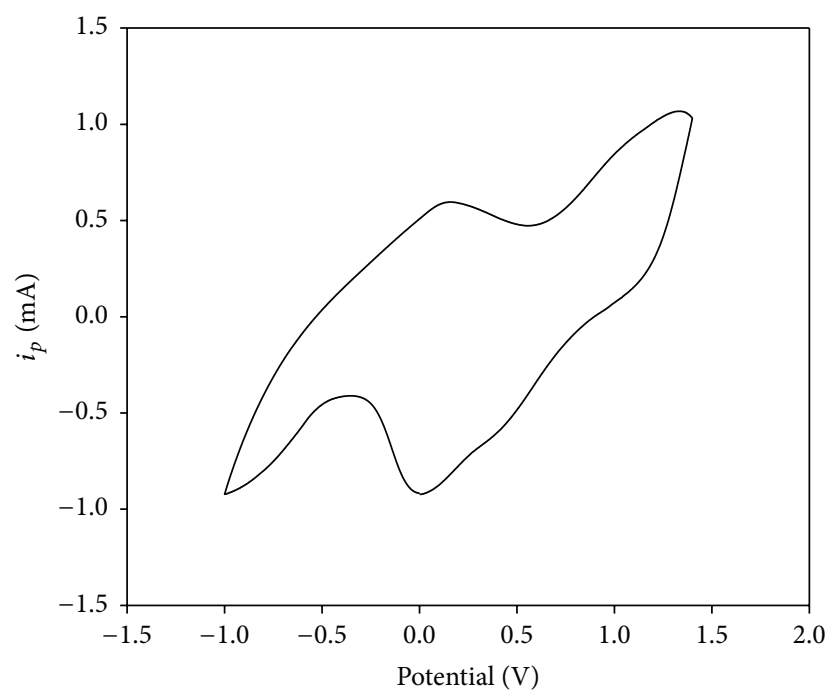

(a)

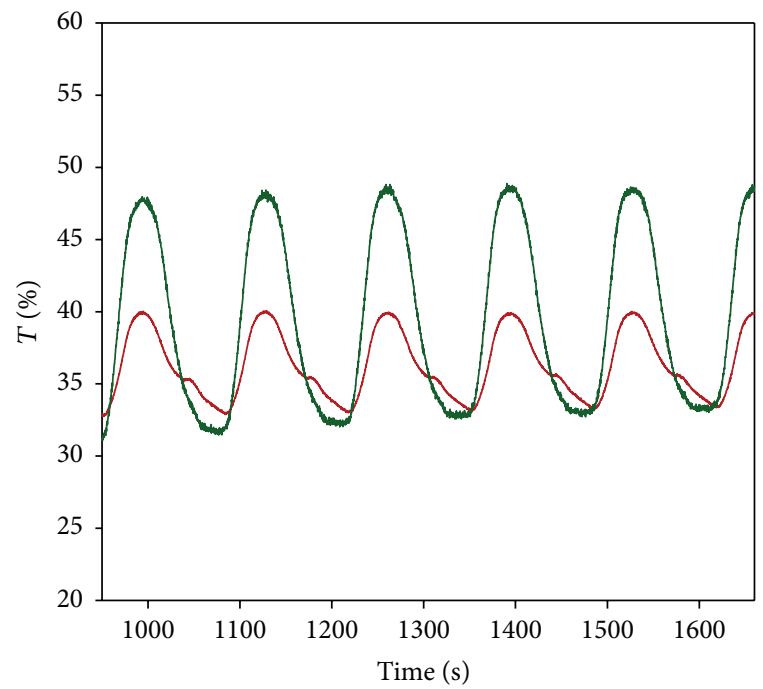

(b)

Figure 8: Cyclic voltammogram (a) and optical modulation (b) annealed at $500^{\circ} \mathrm{C}$. The modulation is shown at $600 \mathrm{~nm}$ (red curve) and at $843 \mathrm{~nm}$ (green curve).

film, in the visible (red) and near-infrared (green) range of the spectrum, respectively. The voltammogram corresponds to the film stabilized electrochemically, after 25 cycles at a scan rate of $30 \mathrm{mV} \cdot \mathrm{s}^{-1}$ and shows a strong peak at $-0.10 \mathrm{~V}$ corresponding to the lithium intercalation. Weaker peaks are seen at $0.20,1.20$, and $0.50 \mathrm{~V}$. Compared to the roomtemperature coated film, the voltammogram has less peaks and they appear to be shifted.

The coloration efficiency of the subzero (SZT) coated films are compared with those of the RT-deposited films. The CE values shown in Table 4 are generally higher in both the visible and the near-infrared range than those corresponding to the room-temperature deposited films. The same tendency is shown by the data given in Table 5 for a few template films studied. The high values of the diffusion coefficient found for the template films confirm the porous nature of the films. The largest CE, that is, $73 \mathrm{~cm}^{2} / \mathrm{C}$, was found for the SZT-coated film annealed at $450^{\circ} \mathrm{C}$ for 1 hour, while, for the RT-deposited films, the highest $\mathrm{CE}$ is reached for the film annealed at $500^{\circ} \mathrm{C}$. It appears that the $\mathrm{CE}$ values were largely influenced by the nanostructures formed at different annealing temperatures. For temperatures of $450^{\circ} \mathrm{C}$ and $500^{\circ} \mathrm{C}$, respectively, the formation of uniform nanorods with high aspect ratios may account for the enhanced CE values.

In the case of porous films (Table 5), the values of the coloration efficiency, as expected, are lower than for the dense films (Table 4).

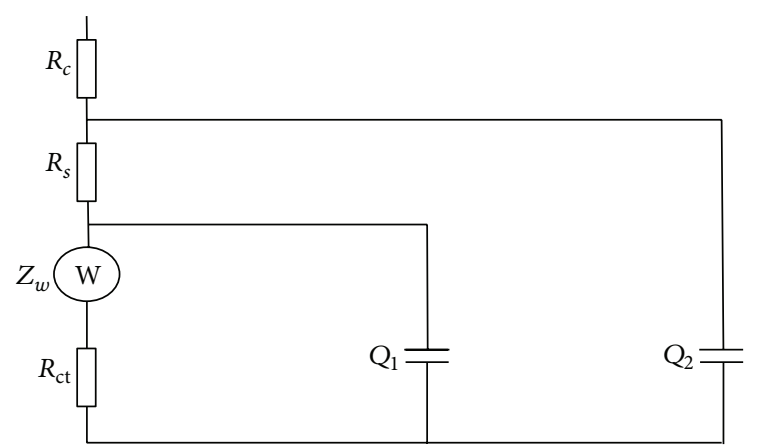

FIGURE 9: Equivalent circuits used to obtain the fitting parameters [37].

3.4. Electrical Impedance Spectroscopy. The equivalent circuit used to obtain the fitting is shown in Figure 9.

In Figure $9, R_{\mathrm{ct}}$ is the resistance of the electrolyte, $R_{s}$ is the resistance representing the adsorption of the lithium ion into the oxide film, $R_{\mathrm{ct}}$ is associated with the charge transfer process occurring at the cathode/electrolyte interface, and $Z_{W}$ is the Warburg impedance associated with the diffusion of the lithium ion through the oxide film. $Q_{1}$ and $Q_{2}$ are constant phase elements.

The electrochemical impedance spectra (Nyquist plots) corresponding to the copolymer template samples (see 
TABLE 6: Fitting parameters corresponding to the subzero temperature dip-coated films.

\begin{tabular}{|c|c|c|c|c|c|c|c|c|c|c|}
\hline \multirow[t]{2}{*}{ Sample } & \multirow{2}{*}{$\begin{array}{c}\text { dc voltage } \\
(\mathrm{V})\end{array}$} & \multirow{2}{*}{$\begin{array}{c}R_{c} \\
\text { ohm }\end{array}$} & \multirow{2}{*}{$\begin{array}{c}R_{s} \\
\text { ohm }\end{array}$} & \multirow{2}{*}{$\begin{array}{c}W \\
\left(\mathrm{~S} \times \mathrm{s}^{0.5}\right)\end{array}$} & \multicolumn{2}{|c|}{$\begin{array}{c}R_{\mathrm{ct}} \\
\mathrm{ohm}\end{array}$} & \multirow{2}{*}{$\begin{array}{c}Q_{1}^{*} \\
\left(S \times s^{a_{1}}\right)\end{array}$} & \multirow[t]{2}{*}{$a_{1}$} & \multirow{2}{*}{$\begin{array}{c}Q_{2}{ }^{*} \\
\left(\mathrm{~S} \times \mathrm{s}^{a_{2}}\right)\end{array}$} & \multirow[t]{2}{*}{$a_{2}$} \\
\hline & & & & & SZT & RT & & & & \\
\hline \multirow{4}{*}{ D } & -0.5 & 378 & 91 & $3.6 \times 10^{-3}$ & 246 & 225 & $82 \times 10^{-6}$ & $700 \times 10^{-3}$ & $69 \times 10^{-9}$ & $809 \times 10^{-3}$ \\
\hline & -0.7 & 343 & 123 & $482 \times 10^{-6}$ & 1158 & - & $135 \times 10^{-6}$ & $650 \times 10^{-3}$ & $61 \times 10^{-9}$ & $817 \times 10^{-3}$ \\
\hline & -1.0 & $43 \times 10^{-9}$ & 502 & $42 \times 10^{-6}$ & 15004 & 206 & $49 \times 10^{-6}$ & $804 \times 10^{-3}$ & $7.1 \times 10^{-6}$ & $303 \times 10^{-3}$ \\
\hline & -1.2 & $5 \times 10^{-6}$ & 493 & $28 \times 10^{-6}$ & 307 & - & $55 \times 10^{-6}$ & $820 \times 10^{-3}$ & $1.7 \times 10^{-6}$ & $514 \times 10^{-3}$ \\
\hline \multirow{3}{*}{$\mathrm{E}$} & -0.5 & 289 & 97 & $12 \times 10^{-3}$ & 40 & 173 & $410 \times 10^{-6}$ & $594 \times 10^{-3}$ & $743 \times 10^{-9}$ & $720 \times 10^{-3}$ \\
\hline & -1.0 & 36 & 357 & $1.1 \times 10^{-3}$ & 101 & 351 & $768 \times 10^{-6}$ & $678 \times 10^{-3}$ & $1.14 \times 10^{-6}$ & $475 \times 10^{-3}$ \\
\hline & -1.2 & 257 & 155 & $764 \times 10^{-9}$ & 110 & - & $469 \times 10^{-6}$ & $624 \times 10^{-3}$ & $645 \times 10^{-9}$ & $697 \times 10^{-3}$ \\
\hline
\end{tabular}

${ }^{*} \mathrm{Q}_{1}, \mathrm{Q}_{2}=$ constant phase element, $\mathrm{S}=$ Siemens $\left(\mathrm{ohm}^{-1}\right), \mathrm{s}=$ seconds, and $a_{1}, a_{2}=$ exponents.

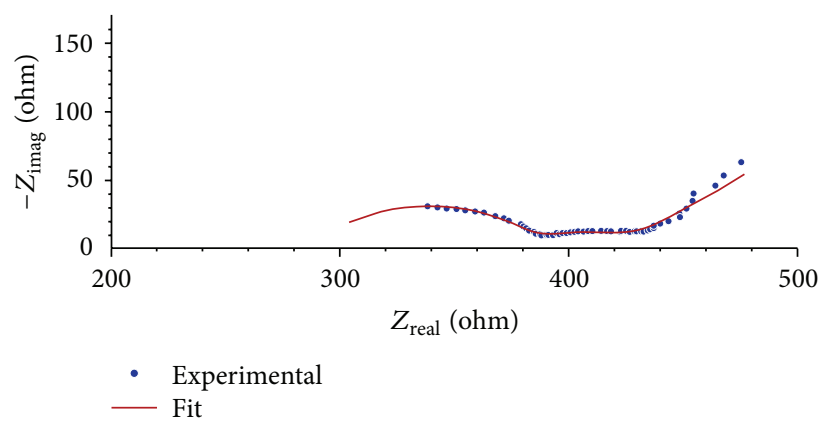

(a)

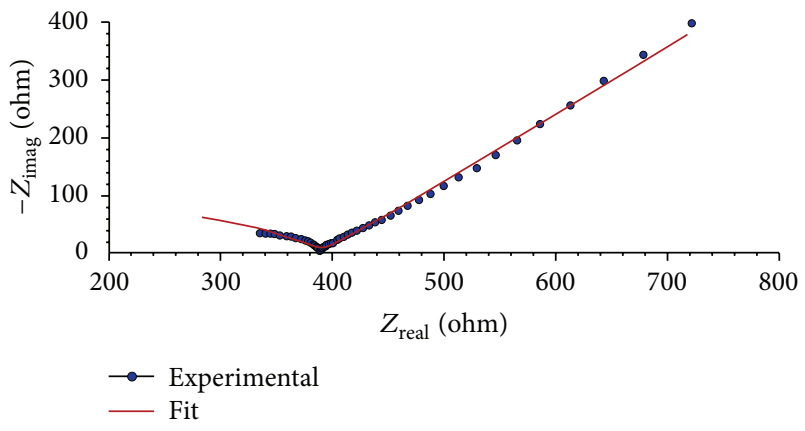

(b)

Figure 10: Nyquist plots corresponding to the triblock copolymer template sample subjected to potentials of $-0.50 \mathrm{~V}$ (a) and $-1.0 \mathrm{~V}$ (b), respectively.

Table 6), subjected to dc potentials of -0.5 and $-1.0 \mathrm{~V}$, respectively, are shown in Figure 10.

When compared to the spectrum measured at $-0.5 \mathrm{~V}$, the curve measured at $-1.0 \mathrm{~V}$ is displaced towards lower resistances-associated with faster kinetics.

The measured electrochemical impedance spectra at different electrode potentials were analyzed. The results show that the Nyquist plot impedance spectra consist of two medium frequency depressed arcs and a low frequency straight line. The low frequency line with a phase angle of $45^{\circ}$ corresponds to the diffusion of lithium ion through the vanadium oxide phase.

In Table 6, the charge transfer resistance values found for the subzero dip-coated samples are compared with those of the room-temperature deposited samples. The charge transfer resistance $\left(R_{\mathrm{ct} 2}\right)$ is the most important parameter related to the $\mathrm{V}^{5+} / \mathrm{V}^{4+}$ reduction process occurring at the electrolyte/ vanadium oxide film. Table 6 shows the values found by curve fitting for the dense and porous samples as well as their dependency on the applied dc potential.

In Table 6, the charge transfer resistance $\left(R_{\mathrm{ct}}\right)$ values of the low-temperature deposited films (SZT) are compared to those corresponding to the films coated at room temperature (RT). The table shows that, for nanorods obtained from the dense film, $R_{\mathrm{ct}}$ is increasing significantly with the applied dc potential, while, for the porous film (template by copolymer),
$R_{\mathrm{ct}}$ is increasing only slightly. Compared with the RTdeposited samples, $R_{\mathrm{ct}}$ values appear to be larger for the dense film and significantly lower for the porous film, indicating that the intercalation of lithium ions is easier in the porous films. This result is in agreement with our previous work on dense and porous $\mathrm{V}_{2} \mathrm{O}_{5}$ films.

\section{Conclusion}

Vanadium oxide thin films have been prepared by a subzero temperature dip-coating method. Structural properties as well as Raman spectroscopy and the morphology characteristics have indicated the presence of a residual compressive stress in the films dip-coated at $-10^{\circ} \mathrm{C}$. The stress is believed to exist due to the formation of microvoids during the deposition process, microvoids that are preserved during the heat treatment of the films. The microvoids are pores that provide additional sites for the intercalation of lithium ions in both dense and porous films, and their presence may also favor the formation of nanostructures that would be responsible for the enhanced electrochromic properties of the vanadium oxide films.

Highly uniform nanorods, interesting for potential applications such as field emission displays and interconnections, have been obtained by annealing at $450^{\circ} \mathrm{C}$ of the subzero coated films. The transformation of the layered film into 
nanorods is thought to happen in a slower fashion and through a mechanism that seems to be different from the transformation of room-temperature deposited films.

The fabrication method proposed is simple and may be used for large surface deposition.

\section{Conflict of Interests}

The authors declare that there is no conflict of interests regarding the publication of this paper.

\section{References}

[1] Q.-H. Wu, A. Thissen, W. Jaegermann, and M. Liu, "Photoelectron spectroscopy study of oxygen vacancy on vanadium oxides surface," Applied Surface Science, vol. 236, no. 1, pp. 473-478, 2004.

[2] M. S. Whittingham, "Lithium batteries and cathode materials," Chemical Reviews, vol. 104, no. 10, pp. 4271-4301, 2004.

[3] L. A. L. de Almeida, G. S. Deep, A. M. N. Lima, I. A. Khrebtov, V. G. Malyarov, and H. Neff, "Modeling and performance of vanadlum-oxide transition edge microbolometers," Applied Physics Letters, vol. 85, no. 16, pp. 3605-3607, 2004.

[4] L. Krusin-Elbaum, D. M. Newns, H. Zeng, V. Derycke, J. Z. Sun, and R. Sandstrom, "Room-temperature ferromagnetic nanotubes, controlled by electron or hole doping," Nature, vol. 431, no. 7009, pp. 672-676, 2004.

[5] I. E. Wachs, "Catalysis science of supported vanadium oxide catalysts," Dalton Transactions, vol. 42, no. 33, pp. 11762-11769, 2013.

[6] B. M. Weckhuysen and D. E. Keller, "Chemistry, spectroscopy and the role of supported vanadium oxides in heterogeneous catalysis," Catalysis Today, vol. 78, no. 1-4, pp. 25-46, 2003.

[7] X. J. Wang, H. D. Li, Y. J. Fei et al., "XRD and Raman study of vanadium oxide thin films deposited on fused silica substrates by RF magnetron sputtering," Applied Surface Science, vol. 177, no. 1-2, pp. 8-14, 2001.

[8] G. Silversmit, H. Poelman, and R. De Gryse, "Influence of magnetron deposition parameters on the stoichiometry of sputtered V2O5 films," Surface and Interface Analysis, vol. 36, no. 8, pp. 1163-1166, 2004.

[9] M. Benmoussa, E. Ibnouelghazi, A. Bennouna, and E. L. Ameziane, "Structural, electrical and optical properties of sputtered vanadium pentoxide thin films," Thin Solid Films, vol. 265, no. 1-2, pp. 22-28, 1995.

[10] S.-H. Lee, H. M. Cheong, P. Liu, and C. E. Tracy, "Improving the durability of amorphous vanadium oxide thin-film electrode in a liquid electrolyte," Electrochemical and Solid-State Letters, vol. 6, no. 6, pp. A102-A105, 2003.

[11] G. J. Fang, Z. L. Liu, Y. Wang, Y. H. Liu, and K. L. Yao, "Synthesis and structural, electrochromic characterization of pulsed laser deposited vanadium oxide thin films," Journal of Vacuum Science and Technology Part A, vol. 19, no. 3, pp. 887892, 2001.

[12] C. V. Ramana, O. M. Hussain, B. S. Naidu, and P. J. Reddy, "Spectroscopic characterization of electron-beam evaporated $\mathrm{V}_{2} \mathrm{O}_{5}$ thin films," Thin Solid Films, vol. 305, no. 1-2, pp. 219-226, 1997.

[13] C. Julien, J. P. Guesdon, A. Gorenstein, A. Khelfa, and I. Ivanov, "The influence of the substrate material on the growth of $\mathrm{V}_{2} \mathrm{O}_{5}$ flash-evaporated films," Applied Surface Science, vol. 90, no. 3, pp. 389-391, 1995.

[14] H. Groult, E. Balnois, A. Mantoux, K. L. Van, and D. Lincot, "Two-dimensional recrystallisation processes of nanometric vanadium oxide thin films grown by atomic layer chemical vapor deposition (ALCVD) evidenced by AFM," Applied Surface Science, vol. 252, no. 16, pp. 5917-5925, 2006.

[15] A. Bouzidi, N. Benramdane, A. Nakrela et al., "First synthesis of vanadium oxide thin films by spray pyrolysis technique," Materials Science and Engineering B: Solid-State Materials for Advanced Technology, vol. 95, no. 2, pp. 141-147, 2002.

[16] K. Jeyalakshmi, K. K. Purushothaman, and G. Muralidharan, "Thickness dependent supercapacitor behaviour of sol-gel spin coated nanostructured vanadium pentoxide thin films," Philosophical Magazine, vol. 93, no. 13, pp. 1490-1499, 2013.

[17] M. Benmoussa, A. Outzourhit, A. Bennouna, and A. Ihlal, " $\mathrm{Li}^{+}$ions diffusion into sol-gel $\mathrm{V}_{2} \mathrm{O}_{5}$ thin films: electrochromic properties," European Physical Journal Applied Physics, vol. 48, no. $1,2009$.

[18] M. Benmoussa, A. Outzourhit, R. Jourdani, A. Bennouna, and E. L. Ameziane, "Structural, optical and electrochromic properties of sol-gel $\mathrm{V}_{2} \mathrm{O}_{5}$ thin films," Active and Passive Electronic Components, vol. 26, no. 4, pp. 245-256, 2003.

[19] D. Liu, Y. Liu, B. B. Garcia et al., " $\mathrm{V}_{2} \mathrm{O}_{5}$ xerogel electrodes with much enhanced lithium-ion intercalation properties with $\mathrm{N}_{2}$ annealing," Journal of Materials Chemistry, vol. 19, no. 46, pp. 8789-8795, 2009.

[20] Z. Wang, J. Chen, and X. Hu, "Electrochromic properties of aqueous sol-gel derived vanadium oxide films with different thickness," Thin Solid Films, vol. 375, no. 1-2, pp. 238-241, 2000.

[21] K. Jeyalakshmi and G. Muralidharan, "Role of annealing duration on the microstructure and electrochemical performance of $\beta-\mathrm{V}_{2} \mathrm{O}_{5}$ thin films," Philosophical Magazine, vol. 94, no. 9, pp. 946-955, 2014.

[22] S. Kim, G. Nam, H. Yoon et al., "Structural, optical, and electrical properties of $\mathrm{ZnO}$ thin films deposited by sol-gel dipcoating process at low temperature," Electronic Materials Letters, vol. 10, no. 4, pp. 869-878, 2014.

[23] M. Alsawafta, A. Almoabadi, S. Badilescu, and V.-V. Truong, "Improved electrochromic properties of vanadium pentoxide nanorods prepared by thermal treatment of sol-gel dip-coated thin films," Journal of the Electrochemical Society, vol. 162, no. 7, pp. H466-H472, 2015.

[24] C.-L. Wu, C.-K. Wang, C.-K. Lin, S.-C. Wang, and J.-L. Huang, "Electrochromic properties of nanostructured tungsten oxide films prepared by surfactant-assisted sol-gel process," Surface and Coatings Technology, vol. 231, pp. 403-407, 2013.

[25] S. Badilescu and P. V. Ashrit, "Study of sol-gel prepared nanostructured $\mathrm{WO}_{3}$ thin films and composites for electrochromic applications," Solid State Ionics, vol. 158, no. 1-2, pp. 187-197, 2003.

[26] M. Sadakane, K. Sasaki, H. Kunioku, B. Ohtani, R. Abe, and W. Ueda, "Preparation of 3-D ordered macroporous tungsten oxides and nano-crystalline particulate tungsten oxides using a colloidal crystal template method, and their structural characterization and application as photocatalysts under visible light irradiation," Journal of Materials Chemistry, vol. 20, no. 9, pp. 1811-1818, 2010.

[27] E. Bica, E. J. Popovici, M. Stefan et al., "Morphological, structural and optical characterization of tungsten trioxide films prepared by sol-gel route: effect of substrate and annealing 
temperature," Digest Journal of Nanomaterials and Biostructures, vol. 6, no. 4, pp. 1935-1946, 2011.

[28] D. Nagao, R. Kameyama, H. Matsumoto, Y. Kobayashi, and M. Konno, "Single- and multi-layered patterns of polystyrene and silica particles assembled with a simple dip-coating," Colloids and Surfaces A: Physicochemical and Engineering Aspects, vol. 317, no. 1-3, pp. 722-729, 2008.

[29] C. C. Chen, "Characterization of porous $\mathrm{WO}_{3}$ electrochromic device by electrochemical impedance spectroscopy," Journal of Nanomaterials, vol. 2013, Article ID 785023, 14 pages, 2013.

[30] O. D. Velev and A. M. Lenhoff, "Colloidal crystals as templates for porous materials," Current Opinion in Colloid and Interface Science, vol. 5, no. 1-2, pp. 56-63, 2000.

[31] Q.-B. Meng, Z.-Z. Gu, O. Sato, and A. Fujishima, "Fabrication of highly ordered porous structures," Applied Physics Letters, vol. 77, no. 26, pp. 4313-4315, 2000.

[32] M. Deepa, A. K. Srivastava, S. N. Sharma, Govind, and S. M. Shivaprasad, "Microstructural and electrochromic properties of tungsten oxide thin films produced by surfactant mediated electrodeposition," Applied Surface Science, vol. 254, no. 8, pp. 2342-2352, 2008.

[33] S. Shin, B. H. Kong, B. S. Kim, K. M. Kim, H. K. Cho, and H. H. Cho, "Over 95\% of large-scale length uniformity in templateassisted electrodeposited nanowires by subzero-temperature electrodeposition," Nanoscale Research Letters, vol. 6, article 467, pp. 1-8, 2011.

[34] L. Mai, W. Guo, B. Hu, W. Jin, and W. Chen, "Fabrication and properties of $\mathrm{VO}_{x}$-based nanorods," The Journal of Physical Chemistry C, vol. 112, no. 2, pp. 423-429, 2008.

[35] C. W. Zou and W. Gao, "Fabrication, optoelectronic and photocatalytic properties of some composite oxide nanostructures," Transactions on Electrical and Electronic Materials, vol. 11, no. 1, pp. 1-10, 2010.

[36] Y. Wang, Z. Li, X. Sheng, and Z. Zhang, "Synthesis and optical properties of $\mathrm{V}_{2} \mathrm{O}_{5}$ nanorods," Journal of Chemical Physics, vol. 126, no. 16, Article ID 164701, 2007.

[37] Y. Zhang, Y.-W. Liu, Y.-S. Cheng, and X.-G. Hu, "Electrochemical impedance spectra of $\mathrm{V}_{2} \mathrm{O}_{5}$ xerogel films with intercalation of lithium ion," Journal of Central South University of Technology, vol. 12, no. 3, pp. 309-314, 2005. 

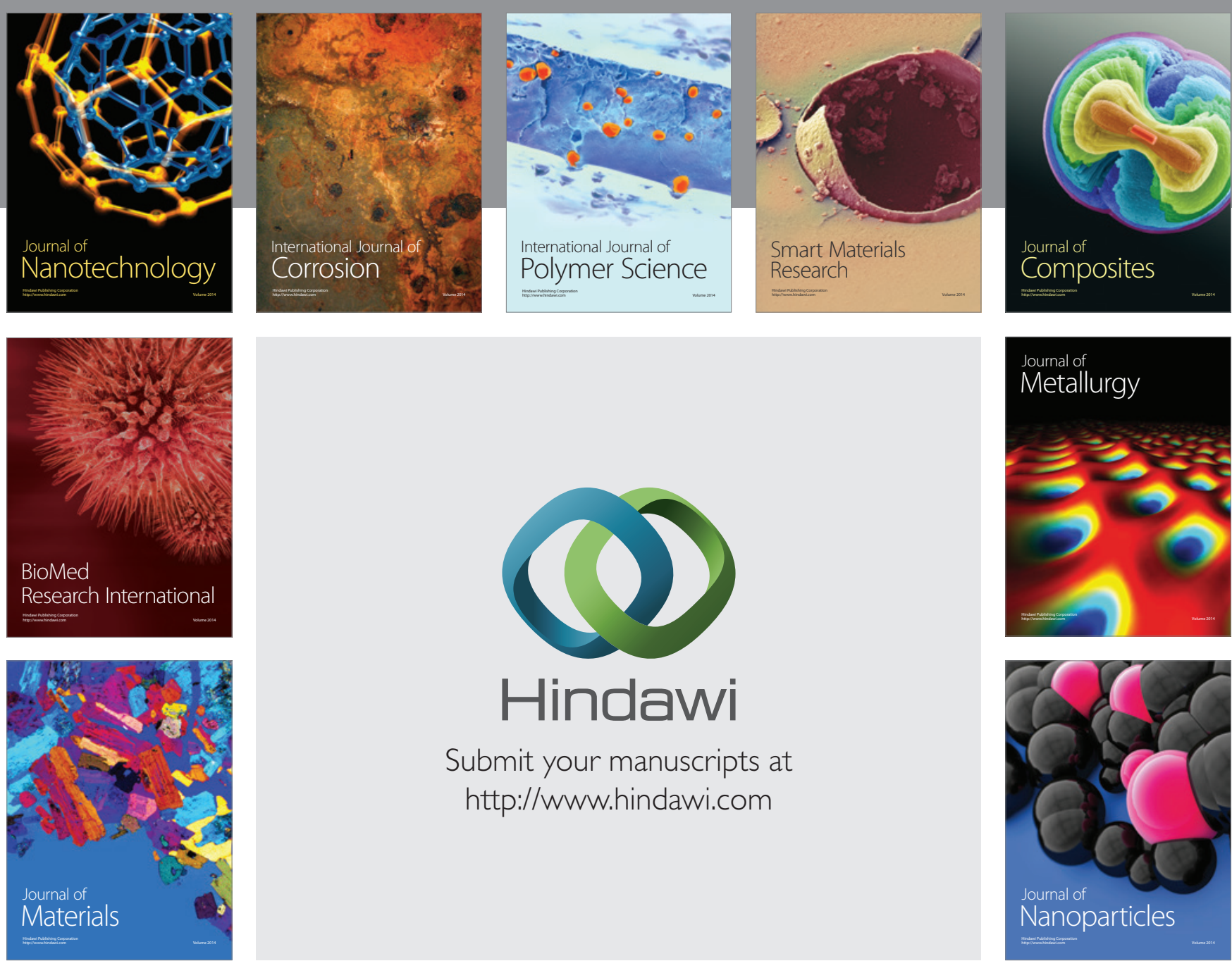

\section{Hindawi}

Submit your manuscripts at

http://www.hindawi.com

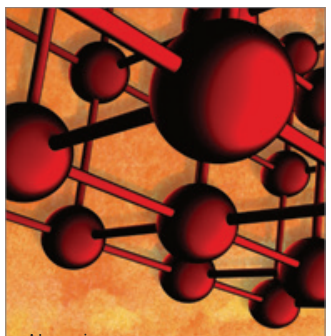

Materials Science and Engineering
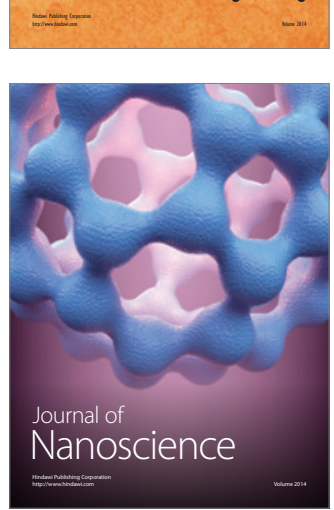
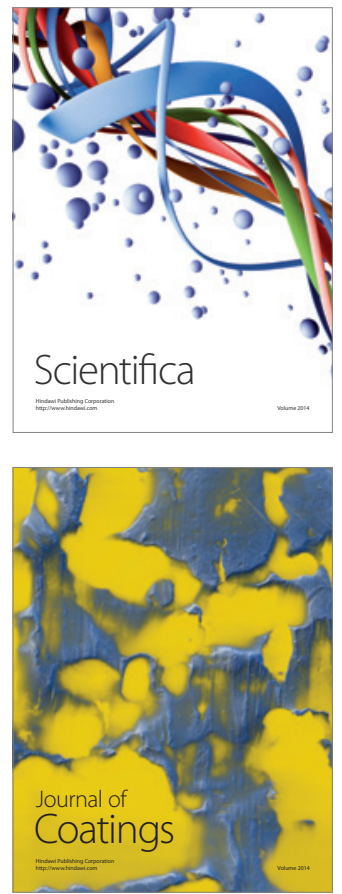
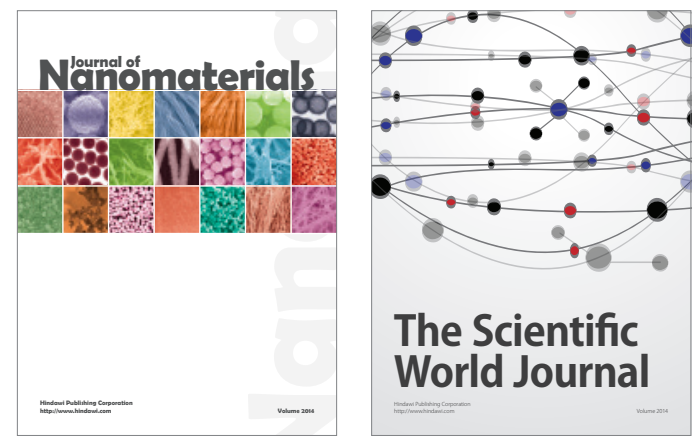

The Scientific World Journal
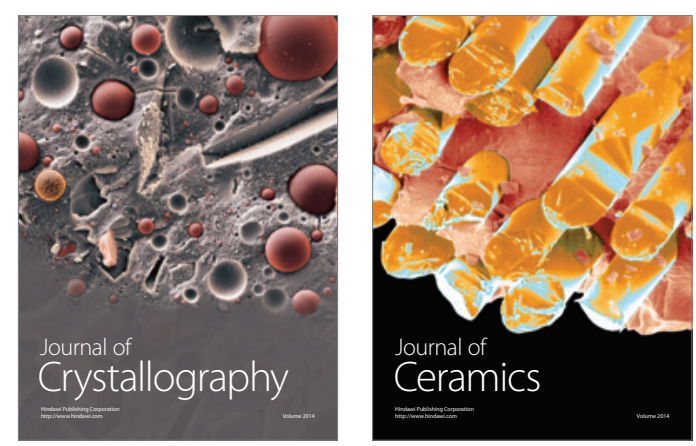
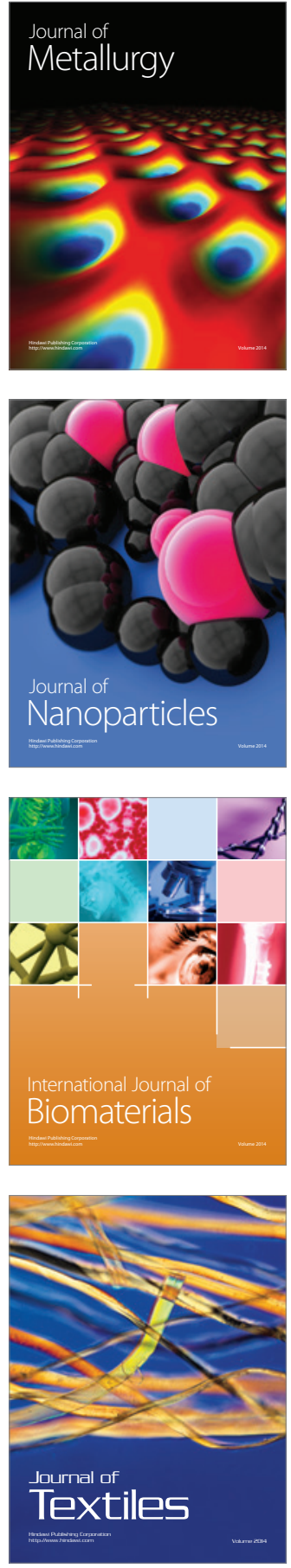